узлов, востребованных на российском рынке, локализация серийного сборочного производства, а также развитие всех необходимых инженерных и технологических компетенций, включая подбор локальных поставщиков современных высокоточных компонентов.

Высококвалифицированные российские специалисты SKF могут производить расчеты шпиндельных узлов любого типа и сложности с помощью специализированного программного обеспечения, а также осуществлять сборку, обкатку, контроль и техобслуживание шпиндельных узлов на базе инжинирингового центра SKF Solution Factory, pacположенного в Москве.

Для обеспечения локальной разработки конструкторской документации и инженерного сопровождения серийного производства шпиндельных узлов было создано специализированное конструкторское бюро на базе МГТУ им. Н. Э. Баумана при НИИКМиТП (Научно-исследовательский институт конструкционных материалов и технологических процессов МГТУ им. Н. Э. Баумана). За несколько лет тесного сотрудничества SKF и университета был реализован ряд разнопрофильных проектов, а также подписано стратегическое соглашение о сотрудничестве.

На данный момент компания SKF готова предложить услуги по расчету, проектированию и локальному производству приводных шпиндельных узлов фрезерной и токарной групп.

Основные этапы работ по созданию шпиндельного узла для серийного производства начинаются с разработки комплекта документации на прототип данного узла, включая уточнение основных технических характеристик изделия, а также расчеты и разработку полного пакета конструкторской документации, что обычно занимает от 1 до 5 мес. Сроки последующего изготовления прототипа изделия - от 3 до 6 мес. После проведения приемочных испытаний в конструкторскую документацию, при необходимости, вносятся дополнительные изменения, и начинается серийное производство изделия.

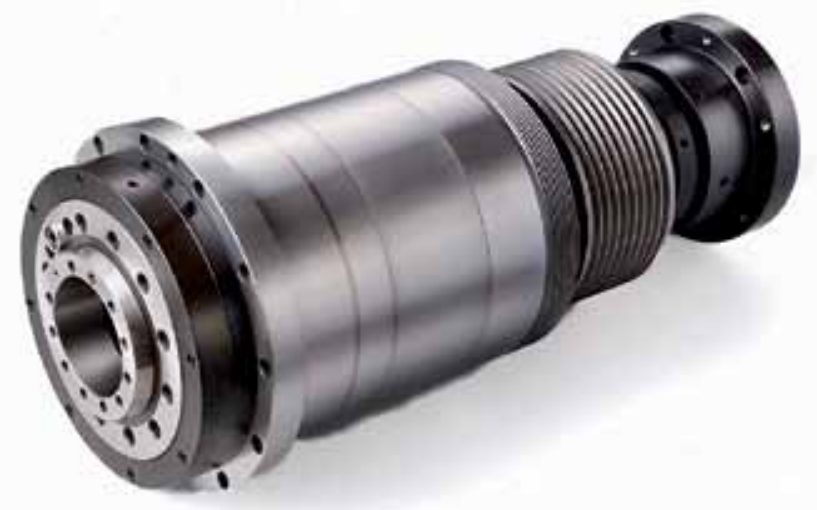

Puc. 1. Токарные шпиндельные узлы SKF

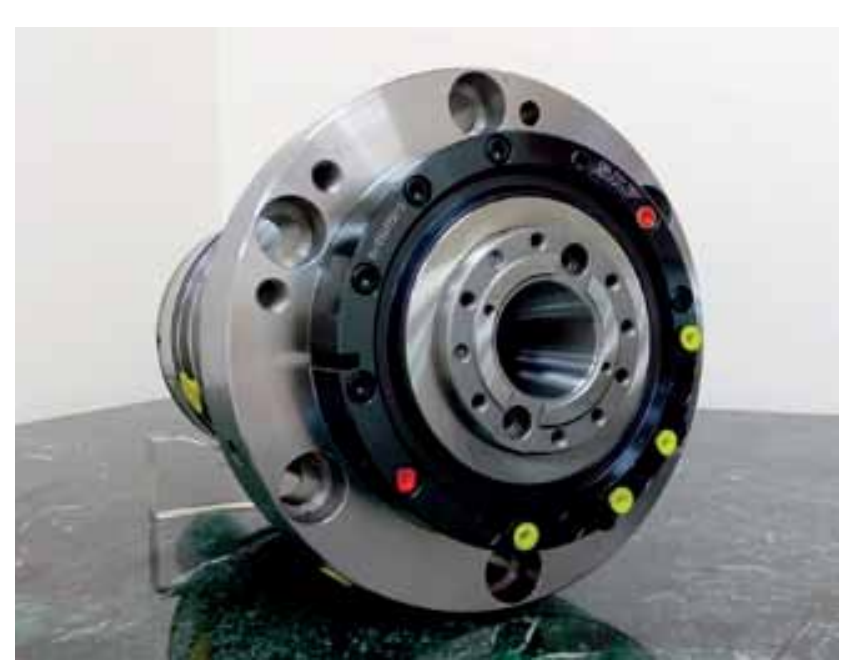

Puc. 2. Фрезерные шпиндельные узлы SKF

Токарные шпиндельные узлы SKF представлены компоновочными типоразмерами А2-5 - A2-11 (рис. 1).

Фрезерные шпиндельные узлы представлены приводными узлами мощностью 12-22 кВт с частотой вращения до 20000 об/мин (рис. 2).

Учитывая многовариантность компоновок высокотехнологичных мотор-шпинделей (рис. 3), расчет, проектирование и производство каждого узла осуществляются в индивидуальном порядке. В качестве примера разработки сложного фрезерного мотор-шпинделя с токарной функцией можно привести 3D-модель шпинделя SKF MT132, рассчитанного и спроектированного в сотрудничестве с МГТУ им. Н. Э. Баумана (рис. 4). В настоящее время ведется подготовка к производству прототипа данного изделия.

Для достижения оптимальных параметров модернизируемого или проектируемого шпиндельного узла инженеры SKF используют специализированное программное обеспечение SKF Spindle Simulator [2]. Данная программа позволяет получить полноценный объект для расчетов благодаря созданию упрощенной двумерной модели шпиндельного узла с привязкой

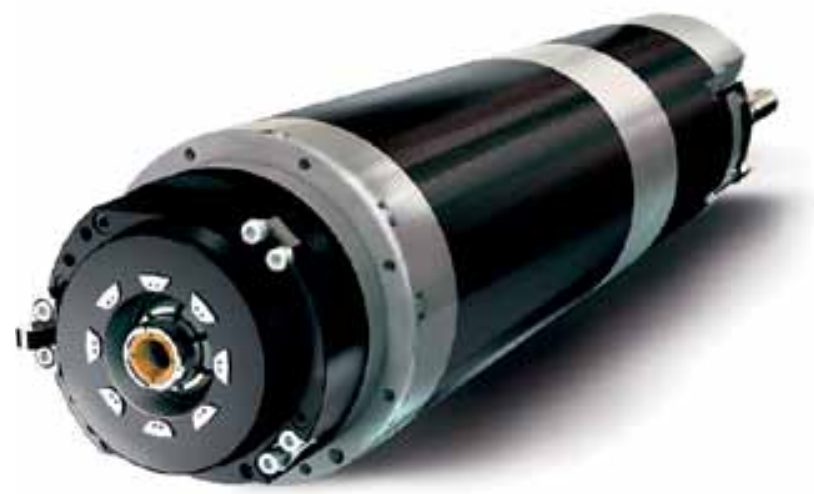

Puc. 3. Мотор-шпиндели SKF 


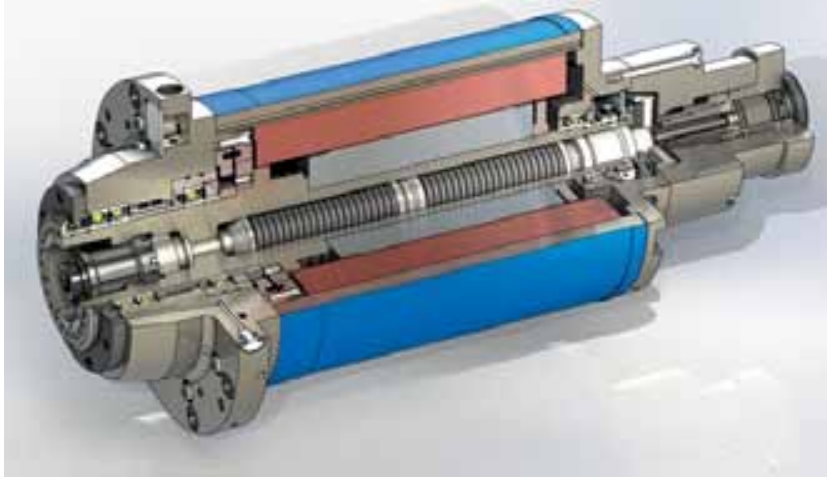

PUC. 4. Трехмерная модель мотор-шпинделя SKF MT132, совместная разработка специалистов SKF и МГТУ им. Н. Э. Баумана

к массогабаритным размерам. Для практической реализации инженерных расчетов в инжиниринговом центре SKF Solution Factory расположен участок по сборке, ремонту и модернизации шпинделей, где, помимо сборки и отладки, также осуществляется обкатка и полная диагностика изделия:

$\rightarrow$ проверка точности ШУ при вращении;

$\rightarrow$ динамические измерения и анализ вибраций ШУ;

$\rightarrow$ тепловое состояние ШУ;

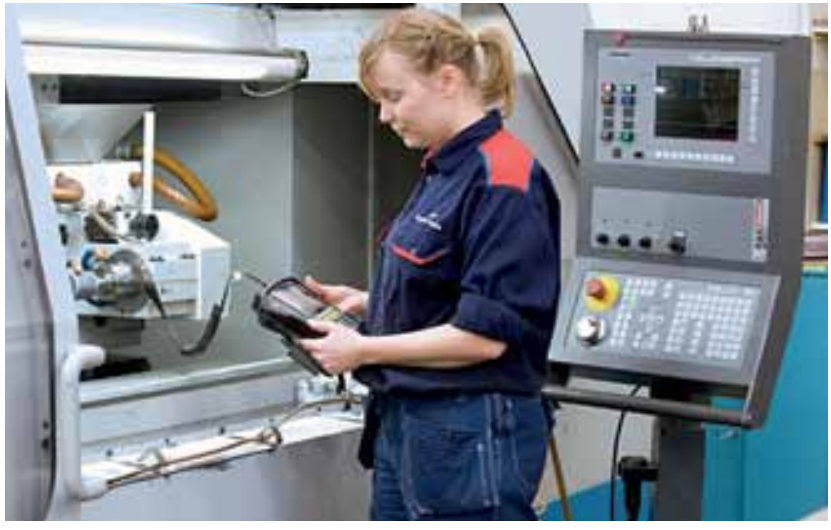

Puc. 5. Диагностика станочного оборудования специалистом SKF

$\rightarrow$ контроль жесткости ШУ;

$\rightarrow$ проверка дисбаланса и балансировка ШУ;

$\rightarrow$ контроль системы смазывания ШУ.

При необходимости специалисты SKF осуществляют техническую поддержку и диагностику шпинделей станков непосредственно на территории клиента (рис. 5).

\section{0 «СКФ»}

тел.: +7 495 510-18-20, e-mail: SKF.Moscow@skf.com

\section{КНИГИ ИЗДАТЕЛЬСТВА «ТЕХНОСФЕРА»}

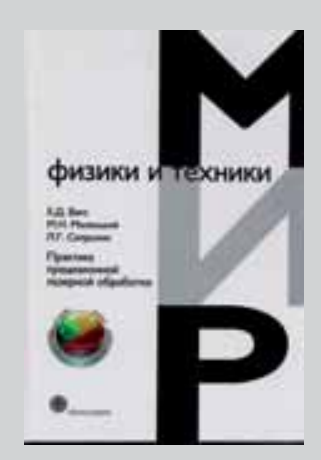

Цена 975 руб.

\section{ПРАКТИКА ПРЕЦИЗИОННОЙ ЛАЗЕРНОЙ ОБРАБОТКИ}

\author{
Е. Д. Вакс, М. Н. Миленький, \\ Л. Г. Сапрыкин
}

Книга посвящена рассмотрению практики прецизионной лазерной обработки. В книге дано определение понятия лазерной прецизионной обработки и представлен обзор основных областей ее применений. Изучены закономерности лазерного сверления, резания, фрезерования и разделения материала импульсами лазерного излучения с длительностью от единиц миллисекунд до сотен фемтосекунд. Проведена классификация процесса лазерного резания материалов, сформулированы и объяснены основные закономерности этого процесса. Приведены практические примеры лазерного фрезерования.

Рассмотрены перспективы и возможности технологии разделения полупроводниковых и диэлектрических материалов за счет использования механизмов лазерного термораскалывания и формирования в материале внутренних зон разрушения. Книга рассчитана на специалистов научно-исследовательских, технологических и производственных подразделений промышленных предприятий, использующих лазерные технологии. Она будет полезной также для студентов и аспирантов, изучающих процессы лазерной обработки.
M.: TЕХHOСФЕРА, 2013. -696 С. +12 С. цВ. вКЛ., ISBN 978-5-94836-339-4 